\title{
Occurrence of extended-spectrum beta- lactamase-producing Enterobacteriaceae, microbial loads, and endotoxin levels in dust from laying hen houses in Egypt
}

Marwa F. E. Ahmed ${ }^{1,2}$, Hazem Ramadan², Diana Seinige ${ }^{3}$, Corinna Kehrenberg ${ }^{4}$, Amr Abd El-Wahab ${ }^{5}$, Nina Volkmann ${ }^{1}$, Nicole Kemper ${ }^{1}$ and Jochen Schulz ${ }^{1 *}$ D

\begin{abstract}
Background: Poultry houses are often highly contaminated with dust, which might contain considerable amounts of microorganisms and endotoxins. The concentrations of microorganisms and endotoxins in dust from laying hen houses in Egypt are unknown. However, to estimate the risks for birds, the environment, and people working in laying hen houses, it is important to gather information about the composition of these dusts. Here we report the microbial loads, the occurrence of antimicrobial-resistant bacteria, and endotoxin concentrations in dust samples from 28 laying hen farms in Dakahliya Governorate, Egypt, and discuss the results relevant to the literature.

Results: Pooled settled dust samples $(n=28)$ were analyzed for total viable counts of bacteria and fungi $(C F U / g)$, the occurrence of extended-spectrum beta-lactamase (ESBL)-producing Enterobacteriaceae, Salmonella spp., and methicillinresistant Staphylococcus aureus (MRSA), and endotoxin concentrations $(\mathrm{ng} / \mathrm{g})$. The means and standard deviations of total viable counts were $7.10 \times 10^{8} \pm 2.55 \times 10^{9} \mathrm{CFU} / \mathrm{g}$ for bacteria and $5.37 \times 10^{6} \pm 7.26 \times 10^{6} \mathrm{CFU} / \mathrm{g}$ for fungi. Endotoxin levels varied from $2.9 \times 10^{4}$ to $6.27 \times 10^{5} \mathrm{ng} / \mathrm{g}$. None of the tested samples contained Salmonella spp. or MRSA. In contrast, by direct plating, Enterobacteriaceae were found frequently $(57 \% ; n=16)$, and suspected ESBLproducing Enterobacteriaceae occurred in $21 \%(n=6)$ of the sampled barns. Using an enrichment method, the detection of Enterobacteriaceae and suspected ESBL-producing Enterobacteriaceae increased to 20 and 16 positive barns, respectively. Taking results from both methods into account, Enterobacteriaceae and suspected ESBL-producing Enterobacteriaceae were detected in 23 barns Overall, 100 ESBL suspected isolates (Escherichia coli, $n=64$; Enterobacter cloacae, $n=20$; and Klebsiella pneumoniae $n=16$ ) were identified to species level by MALDI-TOF MS. Isolates from 20 barns (71\% positive barns) were confirmed as ESBL producing Enterobacteriaceae by the broth microdilution test.
\end{abstract}

Conclusions: Dust in Egyptian laying hen houses contains high concentrations of microorganisms and endotoxins, which might impair the health of birds and farmers when inhaled. Furthermore, laying hens in Egypt seem to be a reservoir for ESBL-producing Enterobacteriaceae. Thus, farmers are at risk of exposure to ESBL-producing bacteria, and colonized hens might transmit these bacteria into the food chain.

Keywords: Laying hens, Settled dust, Bacteria, Fungi, ESBL, Enterobacteriaceae, Endotoxins

\footnotetext{
* Correspondence: jochen.schulz@tiho-hannover.de

'Institute for Animal Hygiene, Animal Welfare and Farm Animal Behaviour, University of Veterinary Medicine Hannover, Foundation, Hannover, Germany Full list of author information is available at the end of the article
}

(c) The Author(s). 2020 Open Access This article is licensed under a Creative Commons Attribution 4.0 International License, which permits use, sharing, adaptation, distribution and reproduction in any medium or format, as long as you give appropriate credit to the original author(s) and the source, provide a link to the Creative Commons licence, and indicate if changes were made. The images or other third party material in this article are included in the article's Creative Commons licence, unless indicated otherwise in a credit line to the material. If material is not included in the article's Creative Commons licence and your intended use is not permitted by statutory regulation or exceeds the permitted use, you will need to obtain permission directly from the copyright holder. To view a copy of this licence, visit http://creativecommons.org/licenses/by/4.0/. The Creative Commons Public Domain Dedication waiver (http://creativecommons.org/publicdomain/zero/1.0/) applies to the data made available in this article, unless otherwise stated in a credit line to the data. 


\section{Background}

The occurrence of organic dust particles on poultry farms, which are formed of both viable and non-viable particles, can pose a serious risk to bird production and stockmen health [1]. Airborne dust or settled dust from surfaces in livestock buildings could contain plant particles, particles from food, fecal particles, epithelia, bacterial cells and spores, fungi and fungal spores, viruses, endotoxins, mycotoxins, and antibiotic agents [2]. The amount and the composition of particles in poultry houses are affected by factors such as housed species, stocking density, age and fattening period of the birds, feeding system, antibiotic treatment, bedding material, humidity, ventilation system, and application of hygienic measures [3, 4]. Respiratory diseases of both humans and animals have mainly multifactorial causes, and the quantity and quality of airborne dust play an important role [5]. Dust in poultry houses, for instance, can contain several inflammatory agents, such as endotoxins and (1-3)-B-D-glucan [6]. Endotoxins are lipopolysaccharides of Gram-negative bacteria that can induce an inflammatory response in humans after inhalation [7]. High endotoxin burdens can also be associated with inflammations and infections of animals [8]. Furthermore, dust in poultry houses can act as a reservoir for zoonotic agents and resistant bacteria. Zoonotic Salmonella species (spp.) can occur and survive in dust from laying hen houses, and they can be transmitted horizontally via an airborne route [9]. This might also enhance the spread within a flock, and that can be associated with a higher risk of contaminated eggs [10]. Another risk is the transmission of potentially harmful microorganisms from animals to farmers. For instance, farmers who frequently come into contact with livestock-associated methicillin-resistant Staphylococcus aureus (LA-MRSA) have a higher risk of becoming colonized with these bacteria than those persons having no contact with farm animals [11]. Direct contact with colonized animals and frequent contact with contaminated surfaces and inhaling contaminated air are assumed to contribute to nasal colonization [11, 12]. Livestockassociated MRSA isolates harbor the mecA gene, which encodes a product that confers resistance to $\beta$-lactam antibiotics [13]. Therefore, screening of dust samples, which is an established method for investigating the LA-MRSA occurrence on farms, can contribute to estimating the risk for farmers of becoming colonized by resistant pathogens. Besides MRSA, extended-spectrum $\beta$-lactamase (ESBL)producing bacteria were discovered worldwide in poultry $[14,15]$. These bacteria secrete enzymes, $\beta$-lactamases, which confer resistance to $\beta$-lactam antimicrobials, including penicillins, cephalosporins, and monobactams [16]. These $\beta$-lactamases are often located on extrachromosomal mobile genetic elements, such as plasmids [17]. Since plasmids harboring resistance genes can be transferred between bacteria of the same species or different genera, such exchanges increase the development of reservoirs of resistance genes in animals and the environment [18]. The role of dust as a source of ESBL-producing bacteria is unknown. Farmers might be colonized and become carriers [19]. Dust can also be a potential longterm reservoir. For example, a recent study showed that resistant Escherichia coli (E. coli) are able to survive for a considerable period of time in dust from livestock buildings [20].

The studies addressing dust in animal houses have been summarized in a review from Zhao et al. [21]. To our knowledge, there is no information available in the scientific literature concerning viable and non-viable particles in dust from laying hen farms in Egypt. To assess the burden of settled dust from Egyptian laying hen houses with microbial loads, zoonotic agents, resistant bacteria (ESBL producers, MRSA), and endotoxin contents in dust samples from 28 laying hen farms were investigated. Since most studies about farm dust components were conducted in temperate zones [22], our research also aimed to gain more information on the situation in ventilated barns under arid conditions.

\section{Results}

All 28 pool samples showed the growth of total mesophilic bacteria and fungi (Fig. 1). Concerning the age of dust samples, no trends were observed, and no significant associations were found. The number of total mesophilic bacteria in settled dust samples varied from $9.07 \times 10^{6}$ colony-forming units $(\mathrm{CFU}) / \mathrm{g}$ in flock 7 (minimum) to $1.41 \times 10^{10} \mathrm{CFU} / \mathrm{g}$ in flock 26 (maximum), with a mean \pm standard deviation (SD) of $7.10 \times 10^{8} \pm$ $2.55 \times 10^{9} \mathrm{CFU} / \mathrm{g}$. Relative to the bacteria, the total fungal count was clearly lower (minimum of $9.84 \times 10^{4}$ $\mathrm{CFU} / \mathrm{g}$ in flock 26, maximum of $3.67 \times 10^{7} \mathrm{CFU} / \mathrm{g}$ in flock 2, mean of $5.37 \times 10^{6} \pm 7.26 \times 10^{6} \mathrm{CFU} / \mathrm{g}$ ).

Neither Salmonella spp. nor MRSA were detected in dust samples (Table 1). The detection frequency of Enterobacteriaceae was 57\% (16/28 samples) by direct plating. A particularly high number of these bacteria were detected in dust from flock $26\left(4.65 \times 10^{6} \mathrm{CFU} / \mathrm{g}\right)$. The lowest concentration $\left(9.08 \times 10^{2} \mathrm{CFU} / \mathrm{g}\right)$ was measured in flock 28 with a mean $\left(1.72 \times 10^{5} \mathrm{CFU} / \mathrm{g}\right)$ of more than three log steps below the number of the total bacteria count (Fig. 1). Enterobacteriaceae were detected more often by pre-enrichment (20/28 flocks) than by direct plating (Table 1). However, samples from three flocks $[8,9,21]$ showed growth for Enterobacteriaceae with direct plating and no growth was observed after enrichment, resulting in a total of 23 positive samples that corresponded to a percentage of $82 \%$ positive flocks. In comparison to the Enterobacteriaceae results, ESBLproducing Enterobacteriaceae were less frequently 


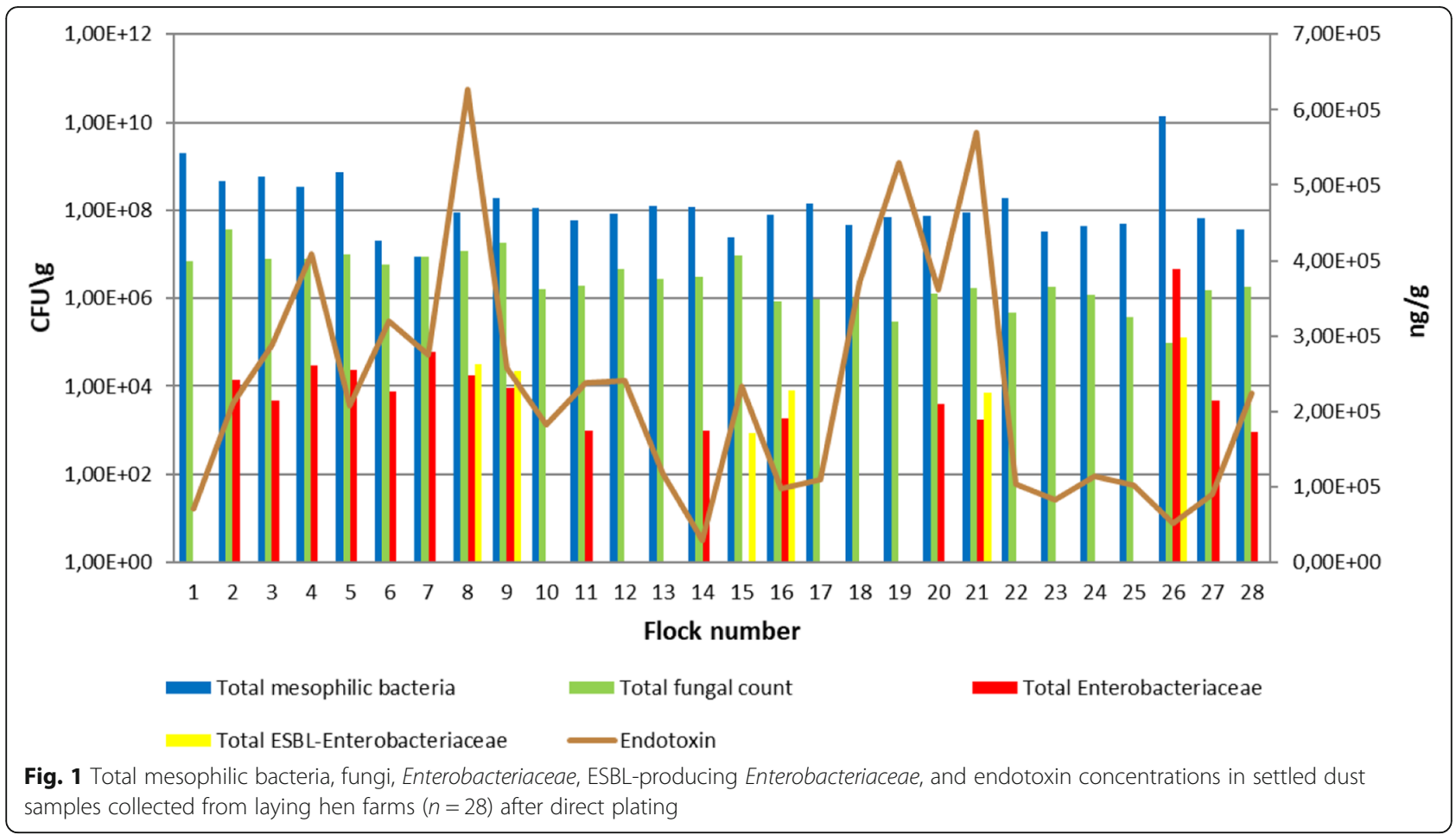

detected by direct plating ( $21 \%$, six positive samples). A high concentration of these bacteria was detected in dust from flock $26\left(1.27 \times 10^{5} \mathrm{CFU} / \mathrm{g}\right)$, while the lowest concentration $\left(8.53 \times 10^{2} \mathrm{CFU} / \mathrm{g}\right)$ was measured in the sample from flock 15 (Fig. 1). The mean of ESBL suspected isolates was $6.98 \times 10^{3} \mathrm{CFU} / \mathrm{g}$. Moreover, the detection level increased after enrichment to 16 positive samples (57\%), including the positive samples from direct plating (Table 1). Additionally, ESBL-producing Enterobacteriaceae were detected in a further seven dust samples from Enterobacteriaceae isolates detected by direct plating on MacConkey agar (MacC) after spreading on Brilliance ${ }^{\mathrm{Tm}}$ ESBL agar (Br-ESBL). Thus, in total, 23 dust samples $(16+7)$ were primarily positive for ESBL-producing Enterobacteriaceae.

The matrix-assisted laser desorption/ionization time of flight mass spectrometry (MALDI-TOF MS) results of collected isolates revealed that $E$. coli $(n=64)$ occurred in all the Enterobacteriaceae positive dust samples (23/23). Enterobacter cloacae (E. cloacae) $(n=20)$ was detected in almost half of the positive samples (12/23), while Klebsiella pneumoniae (K. pneumonia) $(n=16)$ was detected in lowest frequencies in the positive samples (6/23).

ESBL-producing Enterobacteriaceae isolates were confirmed by the broth microdilution test in 20 out of 28 dust samples (71\%).

Endotoxins were detected in all samples. The concentrations varied from $2.9 \times 10^{4}$ to $6.27 \times 10^{5} \mathrm{ng} / \mathrm{g}$, with an average of $2.23 \times 10^{5}$. The detection of endotoxins was not related to the occurrence of cultivable Enterobacteriaceae (Fig. 1).

The detected values of temperature $\left({ }^{\circ} \mathrm{C}\right)$ and relative humidity (\%) are shown in Table 2 . The relative humidity ranged between 50 and $71 \%$ without a clear trend. In contrast, the temperature was lowest in the winter period and highest in the summer period.

Table 1 Detection of Enterobacteriaceae ${ }^{a}$ and ESBL-producing Enterobacteriaceae ${ }^{a}$ and occurrence of MRSA and Salmonella spp. in settled dust from laying hen farms $(n=28)$

\begin{tabular}{|c|c|c|c|c|c|c|c|c|c|}
\hline & \multicolumn{3}{|c|}{$\begin{array}{l}\text { Enterobacteriaceae recovered } \\
\text { from MacC agar plate }\end{array}$} & \multicolumn{4}{|c|}{$\begin{array}{l}\text { ESBL Enterobacteriaceae } \\
\text { recovered from } \mathrm{Br}-\mathrm{ESBL} \\
\text { agar plate }\end{array}$} & \multirow[t]{2}{*}{$\begin{array}{l}\text { MRSA on } \\
\text { CHROM } \\
\text { agar (PE) }\end{array}$} & \multirow[t]{2}{*}{$\begin{array}{l}\text { Salmonella } \\
\text { spp. on MSRV } \\
\text { Agar (PE) }\end{array}$} \\
\hline & $\mathrm{DP}$ & PE & Total positive & $\mathrm{DP}$ & DP MacC & PE & Total positive & & \\
\hline Positive samples & 16 & 20 & 23 & 6 & 7 & 16 & 23 & 0 & 0 \\
\hline Percent (\%) & 57 & 71 & 82 & 21 & 25 & 57 & 82 & 0 & 0 \\
\hline
\end{tabular}

MacC MacConkey, Br-ESBL Brilliance Extended Spectrum Beta Lactamase, MRSA Methicillin-resistant Staphylococcus aureus, MSRV Modified Semi-solid RappaportVassiliadis, DP Direct Plating, PE Pre-Enrichment

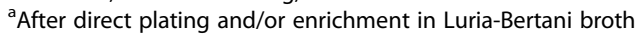


Table 2 Temperature $\left({ }^{\circ} \mathrm{C}\right.$ ) and relative humidity (\%) during the collection of settled dust in laying hen farms $(n=28)$ at different seasons

\begin{tabular}{|c|c|c|c|}
\hline Farm & Season & Temperature $\left({ }^{\circ} \mathrm{C}\right)$ & Relative humidity (\%) \\
\hline 1 & Summer & 30.4 & 63.2 \\
\hline 2 & Summer & 24.2 & 58.4 \\
\hline 3 & Summer & 25.1 & 60.9 \\
\hline 4 & Summer & 22.4 & 60.9 \\
\hline 5 & Summer & 25.1 & 66.0 \\
\hline 6 & Fall & 24.4 & 70.2 \\
\hline 7 & Fall & 28.6 & 56.2 \\
\hline 8 & Fall & 26.9 & 66.3 \\
\hline 9 & Fall & 22.5 & 64.2 \\
\hline 10 & Fall & 23.1 & 61.9 \\
\hline 11 & Fall & 26.4 & 56.6 \\
\hline 12 & Winter & 20.2 & 53.3 \\
\hline 13 & Winter & 21.7 & 54.1 \\
\hline 14 & Winter & 21.8 & 68.5 \\
\hline 15 & Winter & 24.9 & 65.1 \\
\hline 16 & Spring & 20.5 & 57.3 \\
\hline 17 & Spring & 23.1 & 67.7 \\
\hline 18 & Spring & 21.4 & 71.1 \\
\hline 19 & Spring & 23.2 & 55.4 \\
\hline 20 & Spring & 26.9 & 53.8 \\
\hline 21 & Spring & 26.2 & 62.9 \\
\hline 22 & Spring & 23.3 & 57.8 \\
\hline 23 & Spring & 26.6 & 69.3 \\
\hline 24 & Summer & 25.2 & 58.9 \\
\hline 25 & Summer & 27.8 & 49.8 \\
\hline 26 & Summer & 29.5 & 65.8 \\
\hline 27 & Summer & 25.6 & 65.2 \\
\hline 28 & Summer & 28.3 & 55.6 \\
\hline
\end{tabular}

Correlation analysis revealed a low correlation between the total bacteria count and the age of stored samples $\left(\mathrm{r}_{\mathrm{SP}}=0.3959, p=0.0370\right)$ (Table 3$)$. The regression analysis showed that the total bacteria count was associated significantly with the age of stored samples only in the case of the concentrations of Enterobacteriaceae $(p<0.0001, \mathrm{~F} 41.25)$.

\section{Discussion}

Multiple studies from Europe have reported that sedimentation and airborne dust from broiler and turkey barns and layer hen houses can contain high microbial loads and endotoxin concentrations when compared to other farm animals, such as cattle or pigs $[2,23]$. To the authors' knowledge, there are few comparable studies for poultry farms in semi-arid regions. Therefore, the present study is the first to analyze microbial and endotoxin concentrations and the occurrence of resistant bacteria in dust from Egyptian laying hen houses. The only available data published in Egypt are about airborne culturable bacteria and fungi at one small-scale poultry farm [24]. This previous study found air contamination levels with $6.23 \times 10^{5} \mathrm{CFU} / \mathrm{m}^{3}$ and $2.13 \times 10^{3} \mathrm{CFU} / \mathrm{m}^{3}$ for bacteria and fungi, respectively [24]. Furthermore, another longitudinal study performed on three Egyptian broiler farms detected the fungal contamination level of settled dust with averages varying from $1.00 \times 10^{2} \mathrm{CFU} / \mathrm{g}$ 1 day before introducing new chicks into the farm to $3.90 \times 10^{4} \mathrm{CFU} / \mathrm{g}$ at the end of the fourth week of the production cycle [25]. The average total bacterial and fungal count recovered in the current study was $7.10 \times$ $10^{8} \mathrm{CFU} / \mathrm{g}$ and $5.37 \times 10^{6} \mathrm{CFU} / \mathrm{g}$, respectively. Similar results were obtained from a Polish study in which the mean level of total bacteria in settled dust on three laying hen farms amounted to $9.60 \times 10^{8} \mathrm{CFU} / \mathrm{g}$ and for the total fungal count to $2.08 \times 10^{6} \mathrm{CFU} / \mathrm{g}$ [26]. Hartung and Saleh [2] counted $2.0 \times 10^{8}$ to $1.7 \times 10^{9}$ bacteria $(\mathrm{CFU} / \mathrm{g})$ and $4.0 \times 10^{5}$ to $1.2 \times 10^{6}$ fungi (CFU/g) in three different laying hen systems in Germany. The mean average temperatures during the daytime in laying hen houses in Northern Europe ranged between approximately 18 and $22^{\circ} \mathrm{C}$ [27]. The mean temperature measured during the daytime in the presented study was $24.8^{\circ} \mathrm{C}$. The differences between the relative humidity measured in the study by Seedorf et al. [27] and that in our study were less clear. Concerning the temperature, there was no evidence that the number of cultivatable microorganisms in settled dust were mainly affected by climatic differences.

Multiple studies have shown that dust in laying hen houses can be a source of potential pathogens, zoonotic agents, resistant bacteria, and toxic compounds $[1,28]$. Salmonella spp. (as important pathogens) and emerging

Table 3 Spearman's rank correlation coefficient analysis between the total bacteria count and the measured variables ${ }^{a}$

\begin{tabular}{llllllll}
\hline & Fungi & Enterobacteriaceae & ESBL Enterobacteriaceae & Endotoxins & Temperature $\left({ }^{\circ} \mathrm{C}\right)$ & $\begin{array}{c}\text { Humidity }(\%) \\
\text { Age of } \\
\text { dust } \\
\text { sample }\end{array}$ \\
\hline $\mathbf{r}_{\text {SP }}$ & 0.1472 & 0.3941 & 0.7143 & -0.1888 & -0.1388 & 0.0816 & 0.3959 \\
$\boldsymbol{P}$-Value & 0.4547 & 0.1309 & 0.1108 & 0.3359 & 0.4812 & 0.6799 & 0.0370 \\
\hline
\end{tabular}

$r_{S P}$ Spearman's rank correlation coefficient

${ }^{a}$ fungal concentration, Enterobacteriaceae concentration, endotoxin concentration, temperature, humidity and age of the sample 
resistant bacteria (such as MRSA and ESBL-producing bacteria) were selected as indicator organisms for potential hazards. Salmonella spp. can probably be spread by contaminated dust [29], and dust as an environmental sample is sufficient to detect Salmonella spp. in infected flocks [30]. Since no Salmonella spp. were detected in any of the 28 investigated flocks, the prevalence of Salmonella spp. on laying hen farms seems to be low in the Dakahlia province. However, the detection sensitivity on farms could be enhanced by using additional methods, including the investigation of eggs, feces or caeca of the birds [31]. Therefore, we could not state that laying hens in the regions are free from Salmonella spp.

Dust is also a sufficient source to detect MRSA in animal husbandries [32]. European studies have reported that 0.7 to $35 \%$ of poultry flocks, including laying hens, could be colonized with MRSA [33]. Different antibiotic managements in animal husbandries likely lead to lower MRSA prevalences in laying hens compared to broilers or turkeys [34]. Because of the frequent MRSA detection in diseased Egyptian broiler flocks [35, 36], this trend might be true for Egyptian poultry farms. However, no published data are available about the use of antibiotics in Egyptian poultry farms. Another fact is that the survival of LA-MRSA in the dust samples could have been influenced by the storage time. Although Schulz et al. [37] showed that LA-MRSA can stay viable at least for 17 months in poultry dust stored under comparable conditions $\left(4{ }^{\circ} \mathrm{C}\right.$ in the dark), the authors also showed that cultivability is lost during storage. Therefore, we cannot exclude that LA-MRSA occurred originally in the samples. More comprehensive and nationwide studies are necessary to describe the LA-MRSA prevalence in Egyptian poultry flocks.

There are few studies focusing on the level of Enterobacteriaceae in settled poultry dust. Two studies carried out in the Netherlands and Poland found that the mean of E.coli concentrations in settled dust from laying hen barns were $4.1 \times 10^{5}$ and $1.6 \times 10^{5} \mathrm{CFU} / \mathrm{g}$, respectively $[14,26]$, which is comparable to the finding in this study $\left(1.72 \times 10^{5} \mathrm{CFU} / \mathrm{g}\right)$. Skora et al. [26] assumed an association between $E$. coli concentrations and viable bacterial counts. Our findings show a low correlation between total bacterial counts and Enterobacteriaceae concentrations $\left(\mathrm{r}_{\mathrm{Sp}}=0.3941, p=0.1309\right)$, but a significant effect in the regression model. As most cultivable bacteria in dust are Gram-positive cocci [38, 39], this result could not have been expected since Gram-positive cocci are thought to be more resistant against environmental influences [40]. Furthermore, we found a correlation between the total bacteria counts and the age of the stored dust samples. These results are in accordance with previous investigations on the survival of $E$. coli in stored dust samples from broilers [20].
These results demonstrate a high occurrence of ESBLproducing Enterobacteriaceae (71\%) in dust from Egyptian laying hen farms. It should be noted that clinical breakpoints were used for the classification of isolates; if epidemiological cut-off values were used, which are 1-2 dilution steps lower (e.g., according to EU Directive 2013/ $652 / \mathrm{EU}$ ), the percentage would likely have been even higher. These are the first results on this topic from Egyptian laying hen holdings. Confirmed ESBL-producing $E$. coli were isolated from the dusts of 18 farms (64\%). In a Dutch study, the authors found a total of 81 and $40 \%$ ESBL-producing E.coli positive dust samples collected from broilers and laying hens, respectively [14]. The use of antibiotics in laying hens in the present study was unknown. However, in Egypt, there is a lack of effective regulations regarding antibiotic use in animal husbandry for both the treatment and prevention of diseases, or, in many cases, as growth promoters, especially in the poultry sector [41]. This could explain the differences between the current study and the Dutch study, as the inappropriate use of antibiotics in both animals and humans is the main driver for the increase in multi-drug-resistant bacteria [42, 43]. Antibiotic-resistant bacteria in dust are most probably a result of fecal particles in the dust [20]. Their detection in dust means that the environment can be contaminated both by airborne emissions and by spreading manure.

The average detection level of ESBL-producing Enterobacteriaceae was $6.98 \times 10^{3} \mathrm{CFU} / \mathrm{g}$. This shows that ESBLproducing Enterobacteriaceae are only a small part of total culturable bacteria $\left(7.10 \times 10^{8} \mathrm{CFU} / \mathrm{g}\right)$, and concentrations can be below the detection limit of quantitative methods. It is known that the pre-enrichment of bacteria in environmental samples can lower the detection limit of ESBLproducing Enterobacteriaceae [44, 45]. In the present study, the pre-enrichment of bacteria in settled dust samples increased the detection rate of Enterobacteriaceae from 71 to 82\% and for ESBL-producing Enterobacteriaceae from 21 to $57 \%$. It seems that pre-enrichment is a useful method for more sensitive detection of resistant Enterobacteriaceae in dust from poultry houses. However, it should also be considered that AmpC-forming E. coli might not have been detected due to a pre-selection on Brilliance ESBL agar. However, AmpC-producing E. coli also show reduced susceptibility to cephalosporins, so that a higher proportion of isolates with resistance could still be present.

Many environmental investigations showed that poultry houses contain a higher amount of airborne microorganisms and endotoxin concentrations than other animal houses $[23,46]$. The results of the presented study show that the settled dust in Egyptian laying hen houses was polluted with high levels of bacterial endotoxins. The median concentrations of endotoxin found in the samples of settled dust in the present study are similar to those reported in earlier studies [2]. Endotoxin concentrations did 
not correlate significantly with the total bacterial concentrations and Enterobacteriaceae concentrations. This can be explained by the fact that most bacteria in poultry house dust are Gram-positive and that endotoxins can be either from dead or viable but non-culturable bacteria or from Gram-negative bacteria of other families [47]. However, the concentration of airborne endotoxins was not investigated in the presented study. Nonetheless, high concentrations of airborne dust carrying endotoxins can be suspected in littered laying hen houses $[48,49]$. Therefore, a considerable and potentially harmful exposure of farmers or other persons working routinely in laying hen houses can be expected [50]. To prevent negative health effects in humans by exposure to contaminated dust in laying hen farms, it is recommended to wear efficient dust masks while working in such farms. Negative effects on the health of laying hens by endotoxin exposure cannot be excluded [8], but conclusive studies on this have not yet been published.

\section{Conclusion}

In conclusion, this study provides the first set of scientific data on ESBL-producing Enterobacteriaceae, as well as endotoxins and bacterial and fungal loads in settled dust from Egyptian laying hen houses. In the airborne state, dust might impair the health of birds and farmers. Furthermore, laying hens in Egypt seem to be a reservoir for ESBL-producing Enterobacteriaceae. Thus, farmers are at risk of exposure to ESBL-producing bacteria, and colonized hens might transmit these bacteria into the food chain. Prudent use of antibiotics and the implementation of good biosecurity practices in the primary sector are recommended to reduce the occurrence of ESBL-producing Enterobacteriaceae in Egyptian poultry houses. Studies about the use of antibiotics in poultry holdings would be helpful in analyzing associations between the occurrence of antibiotic-resistant bacteria and applied antibiotic agents.

\section{Methods}

\section{Poultry farms}

The studies were conducted at 28 laying hen farms in Dakahlia Province, Egypt, located in $31.0832^{\circ} \mathrm{N}$, $31.4913^{\circ} \mathrm{E}$ latitude. The selection of farms was carried out randomly from different districts across Dakahlia province. The minimum distance between adjacent farms was $10 \mathrm{~km}$. Farmers were contacted by phone maximum a week before sampling. None of the farmers cleaned the barn from dust during the laying period. One flock from each farm was sampled. If farms had more than one flock, the sampled flock was selected randomly. The age of hens during sampling ranged from 24 to 37 weeks. The settled dust samples were collected between the years 2016 and 2017. The hens in all barns were housed on a deep litter system, and the number of animals ranged from 3500 to 10,000 birds (Avian 48 or Hubbard Classic or Ross breed) per flock. Laying hen houses were either mechanically or tunnel ventilated. The feed and water were offered to the laying hens ad libitum.

\section{Dust collection}

From each farm, one pooled sample of settled dust was collected from one flock. Settled dust was collected from ten different elevated surfaces inside the barn, including the drinking system line, feeding system line, and ventilation opening. Dust samples were collected in the morning between 09:00 and 10:00, by brushing settled dust from all sampling points into a sterile container with a sterilized brush. The samples were stored at $4{ }^{\circ} \mathrm{C}$ in the dark for 4 to 18 months in Mansoura University in Egypt before being analyzed retrospectively in a laboratory in Germany at the University of Veterinary Medicine Hannover, Foundation, within the framework of cooperation between Mansoura University and the University of Veterinary Medicine Hannover, Foundation. Dust samples were anonymized before sent to Germany.

\section{Microbiological analysis of dust \\ Enumeration of the total viable mesophilic bacteria and fungi}

The total viable counts of aerobic mesophilic bacteria and fungi in dust samples were examined by plating dilution series from dust suspensions. Dust suspensions were prepared as described by Schulz et al. [20]. Briefly, $0.1 \mathrm{~g}$ dust was added to $10 \mathrm{~mL}$ phosphate buffer saline (PBS) with 0.01\% TWEEN20 (v/v). Then, the suspension was shaken for $30 \mathrm{~min}$ in a water bath at $25^{\circ} \mathrm{C}$. Afterward, the suspension was vortexed for $4 \mathrm{~min}$ (Scientific Industries Inc., Bohemia, NY, USA). Aliquots $(0.1 \mathrm{~mL})$ of suspensions and serial dilutions from these suspensions were plated in triplicate on Tryptone Soya Agar plates (TSA, Oxoid Ltd., Basingstoke, UK) and on DichloranGlycerol (DG-18) agar supplemented with chloramphenicol (Oxoid Ltd) for counting colonies of mesophilic bacteria and fungi colonies, respectively. Negative controls were prepared by inoculating TSA and DG-18 media with $0.5 \mathrm{~mL}$ PBS. TSA plates were incubated for $48 \mathrm{~h}$ at $37^{\circ} \mathrm{C}$, while DG-18 agar plates were incubated at $25^{\circ} \mathrm{C}$ for $5-7 \mathrm{~d}$. After incubation, CFU was counted, and the results were expressed in $\mathrm{CFU} / \mathrm{g}$ of dust.

\section{Detection of Salmonella spp. and MRSA}

For detecting Salmonella spp., an enrichment method was performed. Briefly, $1 \mathrm{~mL}$ dust suspension was added to $9 \mathrm{ml}$ peptone water (PW, Oxoid Ltd) and incubated at $37^{\circ} \mathrm{C}$ for $24 \mathrm{~h}$. Thereafter, three aliquots of $100 \mu \mathrm{L}$ each were added to the surface of Modified Semi-solid 
Rappaport-Vassiliadis (MSRV) agar (Oxoid Ltd) and incubated at $42{ }^{\circ} \mathrm{C}$ for $48 \mathrm{~h}$. The growth of grey-white migrated cells with a turbid zone extending out from the inoculated drop was considered presumptively positive for Salmonella spp. Additionally, the detection of MRSA was also carried out by enrichment. One milliliter of dust suspension was added to $9 \mathrm{ml}$ of Mueller-Hinton broth $(\mathrm{MH}$, Oxoid Ltd) with $6.5 \% \mathrm{NaCl}$ and incubated for $24 \mathrm{~h}$ at $37^{\circ} \mathrm{C}$. Following incubation, $1 \mathrm{ml}$ of the $\mathrm{MH}$ suspension was added to $9 \mathrm{~mL}$ Tryptone Soy Broth (TSB, Oxoid Ltd) containing $75 \mathrm{mg} / \mathrm{L}$ aztreonam and $3.5 \mathrm{mg} / \mathrm{L}$ cefoxitin to grow MRSA aerobically at $37^{\circ} \mathrm{C}$ for $17 \mathrm{~h}$. Thereafter, $10 \mu \mathrm{L}$ of TSB were streaked onto a selective agar CHROMagar MRSA (MAST Diagnostica $\mathrm{GmbH}$, Reinfeld, Germany), and plates were incubated under aerobic conditions for $24 \mathrm{~h}$ at $37^{\circ} \mathrm{C}$. Suspected colonies with pink or mauve coloration were considered to be MRSA. MRSA strain DSM 1182 (Leibniz-Institute DSMZ German Collection of Microorganisms and Cell Culture, Brunswick, Germany) and Salmonella enterica subsp. enterica serovar Livingstone isolates from the bacteria collection of the Institute for Animal Hygiene, Animal Welfare and Farm Animal Behaviour, University of Veterinary Medicine Hannover, Germany were used as growing controls.

\section{Isolation and enumeration of Enterobacteriaceae and ESBL-} producing Enterobacteriaceae

Aliquots $(0.1 \mathrm{~mL})$ from the original dust suspension and from a 10 -fold and 100-fold dilution were plated in triplicate on Br-ESBL agar (Oxoid Ltd) and on MacC agar (Oxoid Ltd) to determine the count of ESBL-producing Enterobacteriaceae and also non-resistant Enterobacteriaceae, respectively. Plates were incubated at $37^{\circ} \mathrm{C}$ for 48 h. Suspected ESBL-producing Enterobacteriaceae and Enterobacteriaceae colonies were counted, and the CFU per gram of dust was calculated. For recovering environmentally stressed ESBL-producing Enterobacteriaceae and Enterobacteriaceae, pre-enrichment of $1 \mathrm{~mL}$ dust suspension was added to $9 \mathrm{ml}$ Luria-Bertani broth (LB, Oxoid Ltd) and incubated at $37^{\circ} \mathrm{C}$ for $24 \mathrm{~h}$ [44]. After incubation, $10 \mu \mathrm{L}$ of the LB broth were streaked onto $\mathrm{Br}-\mathrm{ESBL}$ and MacC agar in duplicate. Plates were incubated for $24 \mathrm{~h}$ at $37^{\circ} \mathrm{C}$ and different Enterobacteriaceae suspected colonies (two to six different colonies, depending on the different appearance on the media) from each media were purified on Columbia blood agar (Oxoid Ltd) and stored in cryovials (CRYOBANK $^{\mathrm{mm}}$, MAST Diagnostica $\mathrm{GmbH}$, Germany) at $-80^{\circ} \mathrm{C}$ for further identification. Negative controls were prepared by inoculating $\mathrm{MacC}$ and $\mathrm{Br}-\mathrm{ESBL}$ media with $0.5 \mathrm{~mL}$ PBS. As growing controls, ESBL-E. coli strain DSM 22664, ESBL-K. pneumoniae strain DSM (26371), and E. coli DSM 1103 (Leibniz-Institute DSMZ German Collection of Microorganisms and Cell Culture, Brunswick, Germany) were streaked onto Br-ESBL agar. Controls were incubated simultaneously with the samples.

When the dust sample showed Enterobacteriaceae colonies only on $\mathrm{MacC}$ agar, either directly or after enrichment but not on Br-ESBL media, the recovered Enterobacteriaceae colonies from $\mathrm{MacC}$ agar were further streaked onto Br-ESBL media and incubated as described above. Recovered Enterobacteriaceae colonies were also purified and stored for further analysis.

\section{Identification of Enterobacteriaceae}

Different Enterobacteriaceae isolates (three to five colonies from each sample), depending on growth characteristics, obtained after direct plating and/or after pre-enrichment from $\mathrm{MacC}$ and $\mathrm{Br}-\mathrm{ESBL}$ media, were purified and further identified by MALDI-TOF MS (Bruker Daltonik GmbH, Bremen, Germany). Sample preparation was carried out in accordance with the protocols provided by the manufacturer using the direct transfer method.

\section{ESBL-producing Enterobacteriaceae determination}

Enterobacteriaceae isolated from dust samples were assigned to ESBL phenotypes by the broth microdilution method following the Clinical and Laboratory Standards Institute (CLSI) document VET01S (CLSI, 2015). Screening of isolates was performed with ceftazidime and cefotaxime at concentrations ranging from 1 to $128 \mu \mathrm{g} / \mathrm{mL}$. Growth at $1 \mu \mathrm{g} / \mathrm{mL}$ or above this antibiotic concentration is suspicious for ESBL production and precondition for a phenotypic confirmatory test. For these phenotypic tests, commercially available microtiter plates (MERLIN Gesellschaft für Mikrobiologische Diagnostika GmbH, Bornheim-Hersel, Germany) were used. The plates contained the following antibiotics and concentrations in two-fold dilution steps: cefepime (CEP) $(1-128 \mu \mathrm{g} / \mathrm{mL})$, cefepime plus clavulanic acid (CMC) $(0.25 / 4-32 / 4 \mu \mathrm{g} / \mathrm{mL})$, ceftazidime (CAZ) $(1-128 \mu \mathrm{g} / \mathrm{mL})$, ceftazidime plus clavulanic acid (CZ $(0.25 / 4-32 / 4 \mu \mathrm{g} / \mathrm{mL})$, cefotaxime (CTX) $(1-128 \mu \mathrm{g} / \mathrm{mL})$, and cefotaxime plus clavulanic acid (C/C) $(0.25 / 4-32 / 4 \mu \mathrm{g} / \mathrm{mL})$. Isolates were considered ESBL-producing positive when the differences in the minimal inhibitory concentration values (MIC values) of cefepime, ceftazidime, and cefotaxime tested individually and in combination with clavulanic acid were greater than or equal to three dilution steps. Quality controls were performed by testing a non-ESBL-producing E.coli (DSM 22664) and an ESBL-producing K. pneumonia (DSM 26371) quality control strain.

\section{Endotoxin levels in dust}

One milliliter of a 10 -fold diluted dust suspension was stored in a tube at $-80^{\circ} \mathrm{C}$ until analysis for determining the endotoxin concentrations. The endotoxin concentrations 
were measured with the Limulus Amebocyte Lysate test (LAL-test, Biowhittaker Inc., Walkersville, MD, USA) in accordance with a standardized chromogen-kinetic procedure (Kinetic-QCL, Lonza Group AG, Basel, Switzerland). Only sterile and pyrogen-free glassware and microplates (Greiner Bio-One International $\mathrm{GmbH}$, Frickenhausen, Germany) were used. The control endotoxin standard ( $E$. coli $\mathrm{O} 55: \mathrm{B} 5)$ was diluted to 50, 5, 0.5, 0.05, and $0.005 \mathrm{EU} /$ $\mathrm{mL}$ to create a calibration curve. The endotoxin activity was indicated in endotoxin units (EU) and calculated to ng/ $\mathrm{g}$ in accordance with the manufactures instructions.

\section{Temperature and humidity}

Air temperature $\left({ }^{\circ} \mathrm{C}\right)$ and relative humidity $(\mathrm{RH} \%)$ were measured by a Digital thermo-hygrometer (Xuzhou Sanhe Automatic Control Equipment Co., Ltd., Xuzhou, China). Values were recorded during the dust collection.

\section{Statistical analyses}

Statistical analyses were performed using the SAS 9.4 software (SAS Institute Inc., Cary, NC, USA). Correlations between the total bacteria count and measured variables (fungal concentration, Enterobacteriaceae concentration, endotoxin concentration, temperature, humidity, and age of sample) were tested using the Spearman's rank correlation coefficient. The chosen variables might directly affect the survival of total bacteria in dust or are potentially closely associated with their count. A linear regression was performed to investigate significant associations of the variables with the total bacteria count. The level of significance was set at $p=0.05$.

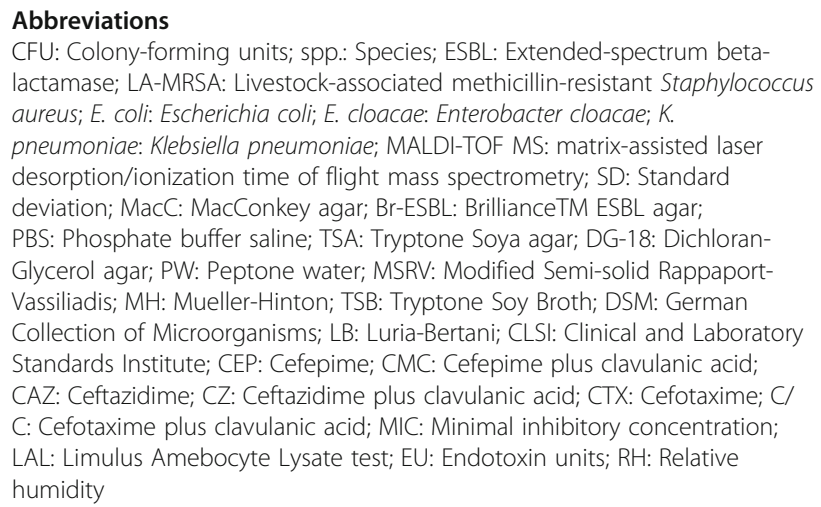

\section{Acknowledgments}

We wish to thank the Egyptian Ministry of Higher Education for supporting the research visit of Dr. Marwa F. E. Ahmed to the Institute for Animal Hygiene, Animal Welfare and Farm Animal Behaviour, University of Veterinary Medicine Hannover, Foundation, Hannover, Germany. Many thanks are also directed to Maria Sember for her laboratory help.

\section{Authors' contributions}

HR sampled the dust and collected environmental parameters. MFEA conducted the microbiological analyses. DS and CK performed the phenotypic confirmation of ESBL bacteria. MFEA, NV, and JS performed the statistical data analyses. MFEA, JS, and NK interpreted the results. MFEA wrote the first draft of the manuscript. AA, JS, and NK corrected and edited the manuscript. All authors reviewed the final version of the manuscript.

Funding

Open access funding provided by Projekt DEAL.

\section{Availability of data and materials}

The datasets used and analyzed during the current study are available from the corresponding author on reasonable request.

\section{Ethics approval and consent to participate}

According to the rules of the Ethical Committee for Animal Experiments at Mansoura University (Mansoura, Egypt), a research protocol must be reviewed by the committee when experiments on animals are conducted in a study. In this study, no experiments on animals were conducted. While collecting the dust samples from laying hen houses, animals were not touched or affected adversely by the sampling method. Prior to the collection of dust samples, farm owners gave informed verbal approval to participate in the study.

\section{Consent for publication}

Not applicable.

\section{Competing interests}

The authors declare that they have no competing interests.

\section{Author details}

${ }^{1}$ Institute for Animal Hygiene, Animal Welfare and Farm Animal Behaviour, University of Veterinary Medicine Hannover, Foundation, Hannover, Germany. ${ }^{2}$ Hygiene and Zoonoses Department, Faculty of Veterinary Medicine, Mansoura University, Mansoura, Egypt. ${ }^{3}$ Institute for Food Quality and Food Safety, University of Veterinary Medicine Hannover, Foundation, Hannover, Germany. ${ }^{4}$ Institute for Veterinary Food Science, Justus-Liebig-University Giessen, Giessen, Germany. ${ }^{5}$ Nutrition and Nutritional Deficiency Diseases Department, Faculty of Veterinary Medicine, Mansoura University, Mansoura, Egypt.

Received: 6 March 2020 Accepted: 4 August 2020

Published online: 24 August 2020

\section{References}

1. David B, Moe RO, Michel V, Lund V, Mejdell C. Air quality in alternative housing systems may have an impact on laying hen welfare. Part I-Dust Animals. 2015:5(3):495-511.

2. Hartung J, Saleh M. Composition of dust and effects on animals. Landbauforsch Volk. 2007:308:111-6.

3. Oppliger A, Charriere N, Droz PO, Rinsoz T. Exposure to bioaerosols in poultry houses at different stages of fattening; use of real-time PCR for airborne bacterial quantification. Ann Occup Hyg. 2008;52(5):405-12.

4. Schulz J, Kemper N, Hartung J, Janusch F, Mohring SAl, Hamscher G. Analysis of fluoroquinolones in dusts from intensive livestock farming and the co-occurrence of fluoroquinolone-resistant Escherichia coli. Sci Rep. 2019:9(1):5117.

5. May $S$, Romberger DJ, Poole JA. Respiratory health effects of large animal farming environments. J Toxicol Env Heal B. 2012:15(8):524-41.

6. Lee SA, Adhikari A, Grinshpun SA, McKay R, Shukla R, Reponen T. Personal exposure to airborne dust and microorganisms in agricultural environments. J Occup Environ Hyg. 2006;3(3):118-30.

7. Thorn J. The inflammatory response in humans after inhalation of bacterial endotoxin: a review. Inflamm Res. 2001;50(5):254-61.

8. Roque $\mathrm{K}$, Shin KM, Jo JH, Kim HA, Heo Y. Relationship between chicken cellular immunity and endotoxin levels in dust from chicken housing environments. J Vet Sci. 2015;16(2):173-7.

9. Gast RK, Mitchell BW, Holt PS. Airborne transmission of Salmonella enteritidis infection between groups of chicks in controlled-environment isolation cabinets. Avian Dis. 1998:42(2):315-20.

10. Gole VC, Torok V, Sexton M, Caraguel CGB, Chousalkar KK. Association between indoor environmental contamination by Salmonella enterica and contamination of eggs on layer farms. J Clin Microbiol. 2014;52(9):3250-8.

11. Cuny C, Wieler L, Witte W. Livestock-associated MRSA: the impact on humans. Antibiotics. 2015;4(4):521-43. 
12. Bos MEH, Verstappen KM, van Cleef BAGL, Dohmen W, Dorado-Garcia A, Graveland $\mathrm{H}$, et al. Transmission through air as a possible route of exposure for MRSA. J Expo Sci Env Epid. 2016;26(3):263-9.

13. Noto MJ, Kreiswirth BN, Monk AB, Archer GL. Gene acquisition at the insertion site for $\mathrm{SCCmec}$, the genomic island conferring methicillin resistance in Staphylococcus aureus. J Bacteriol. 2008;190(4):1276-83.

14. Blaak $H$, van Hoek AH, Hamidjaja RA, van der Plaats RQ, Kerkhof-de Heer L, de Roda Husman AM, et al. Distribution, numbers, and diversity of ESBLproducing $E$. coli in the poultry farm environment. PloS one. 2015;10(8): e0135402.

15. Tekiner $\mathrm{H}$, Ozpinar $\mathrm{H}$. Occurrence and characteristics of extended spectrum beta-lactamases-producing Enterobacteriaceae from foods of animal origin. Braz J Microbiol. 2016;47(2):444-51.

16. Paterson DL, Bonomo RA. Extended-spectrum beta-lactamases: a clinical update. Clin Microbiol Rev. 2005:18(4):657-86.

17. Carattoli A. Resistance plasmid families in Enterobacteriaceae. Antimicrob Agents Ch. 2009;53(6):2227-38

18. Lerminiaux NA, Cameron ADS. Horizontal transfer of antibiotic resistance genes in clinical environments. Can J Microbiol. 2019;65(1):34-44.

19. Dahms C, Hubner NO, Wilke F, Kramer A. Mini-review: Epidemiology and zoonotic potential of multiresistant bacteria and Clostridium difficile in livestock and food. GMS Hyg Infect Control. 2014;9(3):Doc21.

20. Schulz J, Ruddat I, Hartung J, Hamscher G, Kemper N, Ewers C. Antimicrobial-resistant Escherichia coli survived in dust samples for more than 20 years. Front Microbiol. 2016;7:866.

21. Zhao Y, Aarnink AJ, De Jong MC, Groot Koerkamp PW. Airborne microorganisms from livestock production systems and their relation to dust. Crit Rev Env Sci Tec. 2014;44(10):1071-128.

22. Clauß M. Emission of bioaerosols from livestock facilities. In: Methods and results from available bioaerosol investigations in and around agricultural livestock farming. Thünen Working Paper; 2020. Contract No.: 138a.

23. Lawniczek-Walczyk A, Górny RL, Golofit-Szymczak M, Niesler A, Wlazlo A. Occupational exposure to airborne microorganisms, endotoxins and betaglucans in poultry houses at different stages of the production cycle. Ann Agr Env Med. 2013;20:2.

24. Awad AHA, Elmorsy TH, Tarwater PM, Green CF, Gibbs SG. Air biocontamination in a variety of agricultural industry environments in Egypt: a pilot study. Aerobiologia. 2010;26(3):223-32.

25. Ahmed MF, Khalifa MI, EI-Wahab AA, Youssef MA. Indoor fungal load in broiler flocks environment at different stages of production cycle. Int J Poultry Sci. 2016;15(8):297-303.

26. Skora J, Matusiak K, Wojewodzki P, Nowak A, Sulyok M, Ligocka A, et al. Evaluation of microbiological and chemical contaminants in poultry farms. Int J Env Res Pub He. 2016;13(2):192.

27. Seedorf J, Hartung J, Schröder M, Linkert K, Pedersen S, Takai H, et al. Temperature and moisture conditions in livestock buildings in northern Europe. J Agr Eng Res. 1998;70(1):49-57.

28. Just N, Duchaine C, Singh B. An aerobiological perspective of dust in cagehoused and floor-housed poultry operations. J Occup Med Toxicol. 2009;4:13.

29. Galis AM, Marcq C, Marlier D, Portetelle D, Van I, Beckers Y, et al. Control of Salmonella contamination of shell eggs-preharvest and postharvest methods: a review. Compr Rev Food Sci F. 2013;12(2):155-82.

30. Schulz J, Van Hoorebeke S, Hald B, Hartung J, Van Immerseel F, Radtke I, et al. The dynamics of Salmonella occurrence in commercial laying hen flocks throughout a laying period. Avian Pathol. 2011;40(3):243-8.

31. Van Hoorebeke S, Van Immerseel F, De Vylder J, Ducatelle R, Haesebrouck F, Pasmans F, et al. Faecal sampling underestimates the actual prevalence of Salmonella in laying hen flocks. Zoonoses Public Hlth. 2009;56(8):471-6.

32. Friese A, Schulz J, Zimmermann K, Tenhagen BA, Fetsch A, Hartung J, et al, Occurrence of livestock-associated methicillin-resistant Staphylococcus aureus in Turkey and broiler barns and contamination of air and soil surfaces in their vicinity. App Environ Microbiol. 2013;79(8):2759-66.

33. Hartung $M$, Käsbohrer A. Erreger von Zoonosen in Deutschland im Jahr 2011. BfR-Wissenschaft, Berlin, Germany (http://www.bfr bund de/cm/350/ erreger-von-zoonosen-in-deutschland-im-jahr-2011 pdf): Bundesinstitut für Risikobewertung Wissenschaft; 2013

34. Richter A, Sting R, Popp C, Rau J, Tenhagen BA, Guerra B, et al. Prevalence of types of methicillin-resistant Staphylococcus aureus in Turkey flocks and personnel attending the animals. Epidemiol Infect. 2012;140(12):2223-32.
35. Bakeet A, Darwish SF. Phenotypic and genotypic detection of methicillinresistant Staphylococcus aureus (MRSA) in broiler chickens. Assiut Vet Med J. 2014;60(143):142-51.

36. Abd El-Tawab AA, Hofy Fl, Mohamed SR, Amin SH. Characterization of methicillin resistance Staphylococcus aureus isolated from chicken and human. Benha Vet Med J. 2017;32(1):132-7.

37. Schulz J, Qiao F, Weile J, Dreier J, Haetung J. Survival of LA-MRSA in dust of pig and poultry barns In:Bao E Xia, A Shen, B Wu, D Zong, X Proceeding of XVIth International congress of the Society for Animal Hygiene : "Animal Hygiene, Health and welfare as corner stones of sustainable animal production"; 2013; Nanjing.

38. Normand AC, Sudre B, Vacheyrou M, Depner M, Wouters IM, Noss I, et al. Airborne cultivable microflora and microbial transfer in farm buildings and rural dwellings. Occup Environ Med. 2011;68(11):849-55.

39. Normand AC, Vacheyrou M, Sudre B, Heederik DJ, Piarroux R. Assessment of dust sampling methods for the study of cultivable-microorganism exposure in stables. App Environ Microbiol. 2009;75(24):7617-23.

40. Tang JW. The effect of environmental parameters on the survival of airborne infectious agents. J R Soc Interface. 2009:6(Suppl 6):S737-46.

41. World Health Organization. Report on the consultative meeting on antimicrobial resistance for countries in the Eastern Mediterranean Region: from policies to action Sharm el Sheikh, Egypt; 2014 12-14 November 2013.

42. Chantziaras I, Boyen F, Callens B, Dewulf J. Correlation between veterinary antimicrobial use and antimicrobial resistance in food-producing animals: a report on seven countries. J Antimicrob Chemoth. 2013;69(3):827-34.

43. Dahshan H, Abd-Elall AMM, Megahed AM, Abd-El-Kader MA, Nabawy EE. Veterinary antibiotic resistance, residues, and ecological risks in environmental samples obtained from poultry farms. Egypt Environ Monit Assess. 2015;187(2):2

44. Schauss T, Glaeser SP, Gutschow A, Dott W, Kampfer P. Improved Detection of Extended Spectrum Beta-Lactamase (ESBL)-Producing Escherichia coli in Input and Output Samples of German Biogas Plants by a Selective PreEnrichment Procedure. PloS one. 2015:10(3):e0119791.

45. Laube H, Friese A, von Salviati C, Guerra B, Kasbohrer A, Kreienbrock L, et al. Longitudinal monitoring of extended-spectrum-beta-lactamase/AmpCproducing Escherichia coli at German broiler chicken fattening farms. App Environ Microbiol. 2013:79(16):4815-20.

46. Brodka K, Kozajda A, Buczynska A, Szadkowska-Stanczyk I. The variability of bacterial aerosol in poultry houses depending on selected factors. Int J Occup Med Env. 2012;25(3):281-93.

47. Roque K, Lim GD, Jo JH, Shin KM, Song ES, Gautam R, et al. Epizootiological characteristics of viable bacteria and fungi in indoor air from porcine, chicken, or bovine husbandry confinement buildings. J Vet Sci. 2016;17(4):531-8.

48. Le Bouquin S, Huneau-Salaun A, Huonnic D, Balaine L, Martin S, Michel V. Aerial dust concentration in cage-housed, floor-housed, and aviary facilities for laying hens. Poultry Sci. 2013;92(11):2827-33.

49. Springorum A, Hartung J. Airborne moulds, dust and endotoxins in four alternative housing systems for laying hens. Lohmann Information. 2012:41-4.

50. Huneau-Salaun A, Le Bouquin S, Bex-Capelle V, Huonnic D, Balaine L, Guillam MT, et al. Endotoxin concentration in poultry houses for laying hens kept in cages or in alternative housing systems. Brit Poultry Sci. 2011;52(5): $523-30$

\section{Publisher's Note}

Springer Nature remains neutral with regard to jurisdictional claims in published maps and institutional affiliations.

Ready to submit your research? Choose BMC and benefit from:

- fast, convenient online submission

- thorough peer review by experienced researchers in your field

- rapid publication on acceptance

- support for research data, including large and complex data types

- gold Open Access which fosters wider collaboration and increased citations

- maximum visibility for your research: over $100 \mathrm{M}$ website views per year

At $\mathrm{BMC}$, research is always in progress.

Learn more biomedcentral.com/submission 